\title{
Invisibilidade dos negros em "Reflexões sobre Little Rock", de Hannah Arendt: outra história na educação
}

* (Rede Estadual de Ensino da Bahia, Salvador-BA, Brasil)
Resumo: 0 artigo discute a história ignorada por Hannah Arendt no ensaio "Reflexões sobre Little Rock". Após a determinação da Suprema Corte norte-americana para integrar crianças negras e brancas nas mesmas escolas, o governo e parte da população na cidade de Little Rock bloquearam violentamente o acesso dos negros a uma escola comum. Nesse contexto, uma jovem negra foi fotografada enquanto era hostilizada por uma horda de pessoas brancas e impedida de entrar na escola. A partir dessa fotografia, Arendt escreve um de seus primeiros textos em que aborda o tema da educação. Com base nas referências bibliográficas que analisam o período histórico em questão, objetiva-se narrar uma outra história, invisibilizada por Arendt. 0 texto problematiza se a pensadora, antes de analisar a dessegregação racial nas escolas, dialogou com a história dos negros norte-americanos. Por fim, conclui-se que a educação é um espaço de luta contra a invisibilidade, contra o perigo de contar uma única história às crianças e aos jovens.

Palavras-chave: Educação. Invisibilidade. Negros. Hannah Arendt. 
[...] Quando se aproximam de mim, só enxergam o que me circunda, a si próprios ou o que imaginam ver - na verdade, tudo, menos eu. Nem é a minha invisibilidade exatamente uma questão de acidente bioquímico para minha epiderme. A invisibilidade a que me refiro decorre de uma disposição peculiar dos olhos daqueles com quem entro em contato. Uma questão de

construção de sua visão interior, aqueles olhos com os quais olham a realidade através dos olhos físicos (ELLISON, 2013, p. 25).

\section{LITTLE ROCK: OUTRA HISTÓRIA NA EDUCAÇÃO}

O presente artigo objetiva narrar outra história, não contada por Arendt em seu ensaio "Reflexões sobre Little Rock", com base no relato de Elizabeth Eckford, a garota negra hostilizada publicamente, a qual a Hannah Arendt não se preocupou nem mesmo em nomear em seu ensaio, nem em dialogar com os sujeitos envolvidos naquela história. 0 texto reflete também a partir de algumas concepções de Hannah Arendt sobre educação, questionando a presença dos negros, enquanto seres históricos e políticos, no mundo comum.

Era a manhã de 4 de setembro de 1957. A jovem negra de 15 anos, Elizabeth Eckford, admirava seu lindo vestido que costurara junto com a mãe. Com ele iria ao seu primeiro dia de aula em sua nova escola. A senhora Birdie Eckford tentava manter a calma, cuidando dos cabelos e organizando o dinheiro do lanche e os cadernos de sua filha; o pai, o senhor Oscar Eckford, que trabalhara a noite toda, não conseguia dormir, andava de um lado para o outro com o charuto apagado. Era uma casa comum, dentre muitas de trabalhadores negros no Sul dos EUA: ela trabalhava como lavadeira na escola para negros surdos e cegos, e ele na manutenção noturna de vagões de trens (TAYLOR, 2008).

Antes de a jovem Elizabeth sair para seu novo dia, a mãe ainda estava relutante sobre a decisão da filha de estudar em uma nova escola, mas foi convencida de que lá haveria outras oportunidades, até mesmo de frequentar uma universidade, por isso cedeu à pressão. Ela reuniu toda a família para a costumeira oração; relembrou à jovem Elizabeth tudo que the ensinara sobre como se comportar diante das pessoas brancas em situação de perigo. Então, Elizabeth partiu.

Ao descer do ônibus, Elizabeth se viu sozinha. Esperava encontrar seus amigos, oito jovens estudantes negros com os quais iria se juntar para entrar na escola. No entanto, só havia jornalistas, alunos e uma multidão, formada por pessoas brancas. Soldados armados, igualmente brancos, circulavam nos recintos da Little Rock Central High School. Elizabeth acreditou que eles 
estariam ali para que a lei fosse cumprida, para protegê-la e a seus amigos, mas os soldados estavam por determinação do governador do Arkansas para bloquear a entrada dela e a dos outros jovens negros. Ante os olhares da multidão que se aglomerava, Elizabeth continuava corajosamente andando em direção à escola. Ao chegar perto da calçada da escola, uma fileira de guardas levantou suas baionetas, impedindo seu próximo passo. Elizabeth recuou; ingenuamente, pensou: "Talvez essa não seja a entrada, irei até a entrada principal da escola" (TAYLOR, 2008).

Em frente à entrada principal da escola, mais soldados se aproximaram e cruzaram as baionetas, impedindo sua passagem. Quando jovens estudantes brancos chegavam, as baionetas eram abaixadas, eles continuavam e entravam na escola. Elizabeth tentou mais uma vez, as baionetas novamente se cruzaram a sua frente, acompanhadas de um olhar de ódio dos soldados. Entre as baionetas e a multidão que vociferava e se aproximava cada vez mais, Elizabeth encontrou-se sozinha e perdida em meio a rostos, nos quais não se reconhecia.

Perdida no meio da horda branca, Elizabeth lembrou do ensinamento de sua mãe: em situação de risco, busque encontrar proteção junto a alguma mulher idosa. Elizabeth teve seu rosto cuspido por essa mulher. Ainda zonza, sua única atitude foi manter o passo firme, em silêncio, escondendo as lágrimas, até o ponto de ônibus mais próximo. Nessa caminhada, mesmo cercada de jornalistas e fotógrafos, as ameaças vinham de todos os lados, na violência verbal dos adultos e jovens brancos da sua idade que gritavam; e, também, na violência física. 0 risco de linchamento era real. No ponto de ônibus, não suportando presenciar mais aquela agressão, a professora Grace Lourch sentou ao lado de Elizabeth até a chegada do ônibus; embarcaram juntas. Naquele momento, o ocorrido a Elizabeth era divulgado simultaneamente pela rádio local, com relatos de que haviam ferido uma estudante negra que tentava entrar na escola. Seu pai, desesperado, saiu a sua procura; sua mãe, no trabalho, na lavanderia no porão da escola, chorava, quando Elizabeth lá chegou.

A luta pelo direito de estudar em uma escola não segregada continuaria durante todo o ano escolar para Elizabeth e seus oito amigos. Assim que entravam na Little Rock Central High School, grupos de alunos brancos se organizavam para admoestar os nove jovens negros, com a anuência do diretor. Elizabeth relata sua experiência (TAYLOR, 2008, p. 90, tradução nossa): 
Fiquei olhando para a escola - parecia tão grande! Naquele momento, os guardas deixam passar alguns estudantes brancos. A multidão estava quieta. Eu acho que eles estavam esperando para ver o que aconteceria. Quando consegui acalmar minhas pernas, fui em direção ao guarda que havia deixado os estudantes brancos entrarem. Ele não se moveu. Quando tentei seguir, ele ergueu a baioneta e depois os outros guardas chegaram e levantaram suas baionetas. Eles me encararam com um olhar malvado e eu estava muito assustada e não sabia o que fazer. Eu me virei e a multidão veio em minha direção. Eles se aproximaram cada vez mais. Alguém começou a gritar: “Linchem ela! Linchem ela!” Tentei ver um rosto amigável em algum lugar da multidão - alguém que talvez me ajudasse. Olhei para o rosto de uma velha e parecia um rosto amável, mas quando olhei para ela novamente, ela cuspiu em mim. Eles se aproximaram, gritando: "Nenhuma cadela negra vai entrar na nossa escola. Saia daqui!”"

A casa de Elizabeth não tinha telefone. A coordenadora da National Association for the Advancement of Colored People (NAACP), Daisy Bates, não conseguiu informar sobre o novo ponto de encontro e a necessidade da presença dos pais para acompanhar os alunos, o que ensejou a ida solitária de Elizabeth à Little Rock Central High School, a maior escola de Ensino Médio de Little Rock, capital do estado do Arkansas, localizado no centro-sul dos Estados Unidos da América.

O estado do Arkansas descumpria a decisão judicial da Suprema Corte americana, no caso "Brown vs. Board of Education of Topeka”, de 1954, que concluiu: “no campo da educação pública, a doutrina de ‘separado, mas iguais’ ${ }^{2}$ não tem lugar. As instituições educacionais separadas são inerentemente desiguais" (UNITED STATES COURTS, 1954, tradução nossa). O então governador havia deslocado guardas armados com baionetas para impedir o acesso de jovens negros na Little Rock Central High School. Apenas com a posterior intervenção das tropas federais, tentou-se assegurar a permanência e a integridade daqueles nove jovens negros na escola. Esse fato tornou-se símbolo na luta pelos direitos civis dos negros pela dessegregação, inclusive na educação, e ficou mundialmente conhecido como “Little Rock Nine”.

1 "I stood looking at the school - it looked so big! Just then the guards let some white students through. The crowd was quiet. I guess they were waiting to see what was going to happen. When I was able to steady my knees, I walked up to the guard who had let the white students in. He too didn't move. When I tried to squeeze past him, he raised his bayonet and then the other guards moved in and they raised their bayonets. They glared at me with a mean look and I was very frightened and didn't know what to do. I turned around and the crowd came toward me. They moved closer and closer. Somebody started yelling, 'Lynch her! Lynch her!' I tried to see a friendly face somewhere in the mob - someone who maybe would help. I looked into the face of an old woman and it seemed a kind face, but when I looked at her again, she spat on me. They came closer, shouting: 'No nigger bitch is going to get in our school. Get out of here'!" (TAYLOR, 2008, p. 90).

2 "In the filed public education the doctrine of 'separate but equal' has no place. Separate educational facilities are inherently unequal” (UNITED STATES COURTS). 


\section{“REFLEXÕES SOBRE LITTLE RocK”: INVISIBILIDADE E O NÃO DIÁLOGO}

O ensaio "Reflexões sobre Little Rock" (2004) não deve ser considerado uma curva ou algo pontual para compreender o ponto de vista sobre a educação no pensamento de Hannah Arendt. O texto foi escrito por Arendt logo depois dos acontecimentos em 1957, em que Elizabeth Eckford fora hostilizada na entrada da Little Rock Central High School por uma horda de aproximadamente cem pessoas brancas enraivecidas com a decisão da Suprema Corte de integrar os negros nas escolas, destinadas às crianças e aos jovens brancos.

O ensaio “Reflexões sobre Little Rock" (2004), escrito em 1957, foi somente publicado em 1959 pela revista Dissent. Com abordagem sobre temas controversos, como segregação e discriminação, o texto não foi publicado de imediato, sendo adiado pelos editores. Nele observa-se como Hannah Arendt pontua algumas noções sobre público, privado e social, que refletiam sobre seu modo de pensar naquele momento, incidindo na educação.

Embora a autora considere-se uma estranha ao fato ocorrido em Little Rock, essa é uma das primeiras incursões em que a educação foi debatida por Arendt. No referido ensaio, a autora lançou algumas das bases de sua concepção sobre o tema, como a separação entre a política e a educação, demonstrando que o ponto fundamental é a responsabilidade dos adultos na introdução de crianças e jovens no mundo. Arendt escreve (2004, p. 271):

\footnotetext{
A fotografia me pareceu uma caricatura fantástica da educação progressista que, abolindo a autoridade dos adultos, nega implicitamente a sua responsabilidade pelo mundo em que puseram os filhos e recusa o dever de guiar as crianças por esse mundo. Chegamos ao ponto em que se solicita às crianças que mudem e melhorem o mundo? E pretendemos ter as nossas batalhas políticas travadas nos pátios das escolas?
}

Arendt critica a exposição e o abandono de crianças e jovens aos holofotes públicos, deixados para cuidar e resolver sozinhos os problemas que são dos adultos. Segundo Arendt (2004), o acontecimento que envolve a integração racial nas escolas no Sul dos EUA demonstra ser um exemplo de como os adultos perderam a responsabilidade sobre o mundo, transferindo os problemas para os ombros das crianças, em que o campo da educação pode vir a ser invadido pela política e questões sociais como o racismo aos negros, principalmente nos EUA, foco da análise da autora.

Quando o ensaio "Reflexões sobre Little Rock" foi publicado, em inglês, em 1959, dois anos após ser escrito, foi precedido de uma "nota preliminar", que não foi publicada em português. Nesta nota, diz Arendt (2000, p. 231, tradução nossa): 
[...] gostaria de lembrar ao leitor que estou escrevendo como uma estranha. Nunca morei no Sul e até evitei ocasionalmente viagens para estados do Sul porque me levaria para uma situação que eu pessoalmente consideraria insuportável. Como a maioria das pessoas de origem europeia, tenho dificuldade em entender, e muito menos em compartilhar, os preconceitos comuns dos americanos nesta área. Uma vez que o que escrevi pode chocar pessoas boas e ser mal utilizado por pessoas más, gostaria de deixar claro que, como judia, tenho simpatia pela causa dos negros, como por todos os povos oprimidos ou subprivilegiados com certeza, e apreciaria se o leitor fizesse o mesmo. ${ }^{3}$

O ensaio “Reflexões sobre Little Rock” (2004) gerou muita polêmica quando da sua publicação no círculo intelectual que Arendt frequentava, com protestos e críticas dos cientistas políticos negros David Sitz, Melvin Tumin, do filósofo negro Sidney Hook e também da NAACP, aos quais Arendt respondeu em tom provocativo (ARENDT, 2000, p. 231, tradução nossa): “[...] as minorias oprimidas jamais foram o melhor juiz de sua ordem de prioridades em tais assuntos, e há muitas instâncias em que preferem lutar por oportunidades sociais a lutar por direitos humanos ou políticos".

No entanto, atualmente, comentaristas como Baehr (2000, p. 36), May e Kohn (1997), Bohman (1997) ressaltam que o ensaio “Reflexões sobre Little Rock" foi uma tentativa de Arendt de realizar uma categorização teórica do lugar do social e do político. Tais comentaristas deixaram de lado as provocações de Arendt sobre a luta pelos direitos civis dos negros norte-americanos por meio da educação. Por outro lado, alguns pesquisadores negros norte-americanos, a partir da década de 1990, dedicaram-se a questionar a representação dos negros na obra da pensadora, a exemplo de ensaios como: "Heart of darnkness: Africa and African American in the writings os Hannah Arendt" (1996), de Anne Norton; “All power to the people!” (2003), de Joy James e “Hannah Arendt and the Negro Question” (2014), de Kathryn T. Gines.

Em atenção a essas pesquisas, questiona-se a presença dos negros na obra de Arendt e suas implicações na educação, posto que não faz sentido pensar em um mundo comum em que haja a possibilidade de uma educação segregada por uma escola para brancos e outra para negros. A invisibilidade

3 "I should like to remind the reader that I am writing as anoutsider. I have never lived in the South and have even avoided occasionaltrips to Southern states because they would have brought me into a situation that I personally would find unbearable. Like most people of European origin I have difficulty in understanding, let alone sharing, thecommon prejudices of Americans in this area. Since what I wrote mayshock good people and be misused by bad ones, I should like to make itclear that as a jew I take my sympathy for the cause of the Negroes asfor all oppressed or under-privileged peoples for granted and should appreciateit if the reader did likewise" (ARENDT, 2000, p. 232). 
de Hannah Arendt sobre a luta dos direitos civis dos negros norte-americanos e sua concepção de educação no ensaio “Reflexões sobre Little Rock” geram desconforto em alguns de seus leitores e pesquisadores, principalmente nos EUA, não tendo o mesmo reflexo no Brasil.

No fim da década de 1950, entre a escrita e a publicação do ensaio "Reflexões sobre Little Rock”, Hannah Arendt publica, em 1958, outro ensaio, “A crise na educação" (2011). Esses são os dois principais textos da autora sobre o tema educação. Entre os dois textos há distinções - uma das principais é que em “A crise na educação" (2011), Arendt buscou compreender o fenômeno da educação como objeto de uma análise para um exercício do pensamento político, no qual se inserem concepções como a natalidade. A essência da educação, segundo Arendt (2011, p. 247), é “o fato de todos nós virmos ao mundo ao nascermos e de ser o mundo constantemente renovado mediante 0 nascimento". A intrínseca relação entre o sentido da natalidade e a educação se dá por conta de o mundo possuir um passado e uma história, aos quais somos apresentados pela educação.

Ainda no ensaio “A crise na educação”, para Arendt (2011, p. 240), a escola não é o espaço do político por excelência, mas uma dimensão pré-política. A política é feita por iguais, os adultos, não pelas crianças, que ainda não conhecem o mundo e a história. De modo distinto, Arendt, em "Reflexões sobre Little Rock", havia pontuado a relação da educação com as constituições da esfera social. As reivindicações do movimento dos direitos civis eram uma tentativa frustrada dos negros por uma educação de qualidade, sem privilégios, contra a dessegregação racial na escola, criadora de uma ilusão de que se poderiam manifestar na educação questões relativas à esfera política. Assim, confrontou as crianças com um problema político que os adultos não conseguiam resolver: o fim da segregação racial e a igualdade de direitos entre os cidadãos negros e brancos norte-americanos.

Porém, mesmo a autora, ao elaborar a separação entre política e educação, sutilmente considera que os eventos que puseram em risco a vida da jovem Elizabeth Eckford em decorrência da reinvindicação pela integração racial nas escolas não eram do domínio político. A integração racial escolar, para Arendt, pleiteava a atenção para as necessidades dentro das estruturas estabelecidas na sociedade americana, com a finalidade de “ascensão social” dos negros, escolha desses indivíduos, a fim de assegurar uma vida decente e elevar o padrão de vida de suas famílias, sem que houvesse dependência de políticas públicas governamentais para a educação. Lembra Arendt (2004, p. 262-263): 
Em vez de ser convocada a travar uma batalha bem definida pelos meus direitos indiscutíveis

- o meu direito de votar e ser protegida no ato de votar, de casar com quem eu quiser e ser protegida no meu casamento (embora, é claro, não nas tentativas de alguém se tornar cunhado de outro), ou o meu direito de ter oportunidades iguais -, eu sentiria que havia me envolvido num caso de ascensão social; e se escolhesse esse caminho de melhorar a minha situação eu certamente preferiria fazê-lo sozinha, sem ajuda de agências governamentais.

Sem dúvida, até forçar e dar cotoveladas talvez não dependa inteiramente das minhas

inclinações. Eu poderia me ver forçada a tomar essas atitudes para assegurar uma vida decente ou elevar o padrão de vida para a minha família. A vida pode ser muito desagradável, mas seja o que for que ela me force a fazer - e ela certamente não me força a comprar o meu ingresso em bairros restritos -, posso conservar a minha integridade pessoal precisamente porque ajo por coação e por alguma necessidade vital, e não meramente por razões sociais.

Nessa perspectiva, fica evidente uma das formas de invisibilizar a luta dos negros norte-americanos, em que a autora não reconhece como luta política o movimento pela integração racial escolar. Em "Reflexões sobre Little Rock" (2004), percebe-se a ausência de compreensão de Arendt sobre como a reprodução da segregação impede a introdução das crianças, tanto negras quanto brancas, no mundo comum.

Em “Reflexões sobre Little Rock", questiona-se Arendt (2004, p. 261, grifo nosso): "A minha primeira pergunta foi: o que eu faria, se fosse uma mãe negra?". A premissa dessa questão demonstra ser completamente equivocada. 0 problema, em princípio, não é se colocar em um lugar que não é seu, na figura de alguém por quem se tem simpatia, mas não se conhece. O problema é acreditar que se pode pensar a partir disso, sem de fato fazer um esforço para realmente conhecer e ouvir o outro, que é um ser humano com quem se convive no tempo presente. Ao tentar se colocar no lugar de uma mãe negra do Sul, sem o esforço necessário para compreender a história da integração escolar norte-americana, Arendt, uma estranha, intelectual e europeia, argumenta que,

[...] se fosse negra, sentiria que a própria tentativa de começar a dessegregação na educação e nas escolas não tinha apenas deslocado e muito injustamente a carga da responsabilidade dos ombros dos adultos para os das crianças. Estaria também convencida de que há em todo o empreendimento uma implicação de tentar evitar a questão real (ARENDT, 2004, p. 262).

Segundo Arendt (2004, p. 262), a igualdade se dá no âmbito público, entre adultos. No entender da autora, esta deveria ser a questão real a ser reivindicada pelas pessoas negras adultas, americanos do Sul, contra as leis de segregação; diferente, então, da integração forçada nas escolas por uma decisão de Estado, afetando as crianças, que não estão no âmbito da 
igualdade. Para Arendt, a busca da dessegregação na educação e nas escolas deslocava injustamente a responsabilidade do mundo público dos adultos para os ombros das crianças (ARENDT, 2004, p. 262). A proteção à igualdade deveria ser pleiteada pelos negros para os direitos indiscutíveis, como o direito de votar e, também, a guarda ao direito de casamento inter-racial, não na integração forçada nas escolas. Além disso, Arendt escreve:

Se fosse apenas uma questão de educação igualmente boa para os meus filhos, um esforço para lhes conceder igualdade de oportunidades, por que não me pediram que lutasse pelo melhoramento das escolas para crianças negras e pelo estabelecimento imediato de classes especiais para aquelas crianças cujo histórico escolar as torna aceitáveis nas escolas de brancos? (ARENDT, 2004, p. 262).

Os seres humanos, independentemente de sua origem étnica, religiosa ou cultural, tornam-se sujeitos de um mundo comum. Diante da construção do mundo político, em seus diversos aspectos, Arendt destaca, em sua obra, o espaço de ação em seu aspecto público. Hannah Arendt (2016) buscou pensar o sentido do mundo humano que é compartilhado, expondo sua concepção de mundo em "A condição humana":

O mundo comum é aquilo que adentramos ao nascer e que deixamos para trás quando morremos. Transcende a duração de nossa vida tanto no passado quanto no futuro, preexistia à nossa chegada e sobreviverá à nossa breve permanência nele. É isso o que temos em comum não só com aqueles que vivem conosco, mas também com aqueles que aqui estiveram antes e com aqueles que virão depois de nós. Mas esse mundo comum só pode sobreviver ao vir e ir das gerações na medida em que aparece em público (ARENDT, 2016, p. 68).

Se Arendt estivesse mais atenta, poderia ter percebido que a integração racial é a apresentação do mundo comum, do qual os diferentes fazem parte. Assim como a pensadora acreditava que as crianças e os jovens não têm a responsabilidade de levar nos ombros a luta pela dessegregação, crianças e jovens também não devem dar continuidade à segregação, que gera o racismo, o preconceito e a discriminação no mundo. A educação, tida como espaço comum a todos os seres humanos, não pode perpetuar tais reproduções raciais, seja em espaços sociais ou privados, seja na família.

Outra questão criticada por Arendt em "Reflexões sobre Little Rock" foi a decisão da corte judicial de limitar o direito dos pais na escolha de com quem seus filhos devem estar. Nesse sentido, trata-se de uma requisição para a livre associação, à qual apenas os pais teriam direito, não devendo o Estado interferir. Argumenta Arendt (2004, p. 280): 
Forçar os pais a mandar os filhos para uma escola integrada contra a sua vontade significa privá-los de direitos que claramente lhes pertencem em todas as sociedades livres - o direito privado sobre seus filhos e o direito social à livre associação. Quanto às crianças, a integração

forçada significa um conflito muito sério entre a casa e a escola, entre a sua vida privada e a social, e embora esses conflitos sejam comuns na vida adulta, não se pode esperar que as crianças saibam lidar com esses problemas, e assim não se deveria expô-las a eles.

A questão não vislumbrada por Arendt é que o direito de livre associação não deve ser mantido por preconceito, desconhecimento, falta de compreensão da história do outro, violência ou discriminação, que se perpetuam socialmente. A escola deve ser um espaço de compartilhamento entre os diferentes para que as crianças possam conhecer e assim compreender o mundo do qual fazem parte.

No entanto, Elizabeth e seus amigos não estavam sozinhos, nem assumiram o encargo de se responsabilizarem por questões políticas ou sociais. As crianças e os jovens daquela época, no Sul dos EUA, faziam parte de um mundo em que a luta contra a segregação atravessou várias gerações. 0 equívoco de Arendt pode ser notado na fala da própria Elizabeth Eckford, em entrevista sobre o acontecimento daquela manhã de 4 de setembro de 1957. Mesmo com a resistência dos pais em aceitar que fosse para Little Rock Central High School, ela, de modo persistente, os convenceu. Assim, lembra na entrevista à CNN (2004, tradução nossa):

Mesmo que fôssemos uma família da classe trabalhadora, sempre me disseram que eu deveria ir para a faculdade. E, em um ambiente segregado, eu sabia que... o que estava disponível para estudantes brancos era muito melhor que o que estava disponível em uma escola para negros.

Veja, nunca foi um sistema de escola dividido, era separado, mas nunca foi igual. ${ }^{4}$

Arendt (2008, p. 266) tinha conhecimento de que “a questão da cor foi criada por um grande crime na história dos Estados Unidos e só tem solução dentro da estrutura política e histórica da República”, porém não conseguiu compreender que estava presenciando o novo em uma sociedade, em que a discriminação pela cor da pele era legitimada pela lei, por decisões de governo e por uma história de séculos de segregação. Arendt mostrou-se incapaz de dialogar com o movimento negro dos direitos civis e nem ouviu a voz dos envolvidos. Mesmo assim, acreditou que poderia julgar.

4 “Even though we were a working-class family l'd always been told that I ought to, should, and would go to college. And, in a segregated environment I knew that ... what was available to white students was more than, and better than what was available in a Negro school. See, the dual school system, was never, it was separate, but it was never equal" (CNN, 2004). 
Arendt não compreendeu que havia uma história de lutas por direitos, não apenas pelos direitos civis, mas pelo que é mais básico: o direito à vida. As pessoas negras queriam viver sem ter sua integridade ameaçada a cada instante. No entanto, havia o medo real e cotidiano de ser linchado em praça pública, enforcado em uma árvore em razão da cor da pele. A própria Elizabeth ouviu da turba de brancos: "Eles se aproximaram cada vez mais. Alguém começou a gritar: 'Arraste-a sobre esta árvore! Vamos cuidar desse negro!'” (They moved closer and closer. Somebody started yelling, 'Drag her over this tree! Let's take care of that nigger!) (TAYLOR, 2008, p. 90, tradução nossa). Nesse sentido, causa estranheza o argumento de Arendt contrário à integração dos negros na escola dos brancos. Mesmo antes de o regime nazista assumir o poder na Alemanha, Arendt, uma mulher judia, refugiada ainda jovem de sua terra, desde a infância já convivia com ideias antissemitas. Mas podia defender-se enquanto judia, como ela mesma conta que aprendeu com sua mãe:

\section{[...] a diferença era que minha mãe sempre achava que a pessoa não devia se deixar afetar. Tinha de se defender! Quando meus professores faziam comentários antissemitas - geralmente não sobre mim, mas sobre outras meninas judias, alunas judias orientais, sobretudo -, eu devia levantar na mesma hora, sair da sala de aula, ir para casa e contar tudo tintim por tintim. Então minha mãe escrevia uma de suas cartas registradas, e para mim a coisa estava totalmente resolvida (ARENDT, 2007, p. 38).}

Arendt, em sua infância e juventude, viveu na Alemanha, que assegurava a cidadania das pessoas de origem judaica, principalmente daquelas com uma condição mais abastada. A ela foi garantido o direito de frequentar as melhores escolas e universidades, convivendo com intelectuais de várias origens. Embora a violência presente em ambas as histórias seja terrível, há que se reconhecer as diferenças entre a história dos judeus alemães prénazismo e a dos negros norte-americanos na luta pelos direitos civis.

A marginalização social e política das pessoas negras constitui-se tema fundamental na educação para a compreensão do mundo. Esses problemas são resquícios da escravização de pessoas negras, que tiveram seu corpo marcado a ferro desde que colocaram os pés na América e que, por mais de 300 anos, foram tratadas como coisas, mercadorias, tanto no Sul dos EUA quanto no Brasil.

Elizabeth Eckford não teria a mesma sorte que a jovem Arendt se viesse a esboçar uma defesa, enquanto mulher e negra, perante qualquer situação de discriminação e preconceito. Ela correria o risco de ser queimada viva em praça pública, para servir de exemplo contra a insubordinação de um "costume 
social da segregação da América branca” (ARENDT, 2004, p. 270). Ademais, se a mãe de Elizabeth ousasse escrever uma carta a alguma autoridade governamental, o risco seria igualmente compartilhado por toda a família. Diferente de Arendt, que se sentia protegida em casa, para as crianças negras não existia nenhuma guarda ou proteção, mesmo sob o abrigo familiar.

Arendt não esteve atenta à história política dos negros na América do Norte, não se preocupou em investigar e conversar com negros norte-americanos para tentar compreender o porquê daquela luta pelo direito à educação integrada racialmente em Little Rock, para todas as crianças e jovens. Aquela geração de negros norte-americanos pensou a integração racial nas escolas não apenas como acesso a uma educação de qualidade, que Arendt reduz à busca de “ascensão social” (ARENDT, 2004, p. 262), mas como uma renovação do mundo.

Em 1961, a autora revisou “A crise na educação" para o livro Entre o passado e o futuro (2011), retirando da última versão um parágrafo, originalmente publicado em alemão, que fazia menção ao fato ocorrido em Little Rock. Teria Arendt repensado sua posição de que as demandas dos negros norteamericanos contra a segregação nas escolas não eram de cunho social, mas uma reivindicação pela presença dos negros, enquanto sujeitos históricos e políticos, também criadores de um mundo comum, em que suas crianças negras poderiam adentrar pela natalidade?

Tal nuance na posição de Arendt circunscreve-se sobre aqueles que ocupam estes espaços: o pré-político e o social. Ao incidir na concepção de educação de Arendt, será notado que o tratamento despendido pelo pensamento da autora aos negros que lutaram por uma escola não segregada será refletido nas disputas políticas nas universidades americanas, ainda, ligando-os às disputas para as necessidades no âmbito social. O social não era visto por Arendt com bons olhos, pois a educação não era um palco para superação das necessidades, mas de apresentação às crianças e aos jovens do mundo comum e público, que possui uma história.

O escritor negro Ralph Ellison, autor do livro Homem invisível (2013), também criticou os argumentos de Arendt no referido ensaio. Em uma entrevista, parte do livro Who speaks for the Negro? (WARREN, 2014), que reúne as principais personalidades que integraram a luta pelos direitos civis dos negros nos EUA na década de 1960, argumentou Ellison (2014, p. 325, tradução nossa): 
É aqui que Hannah Ernst [Arendt] está bem na contramão em suas reflexões sobre o Little Rock. Ela não tem nenhuma ideia sobre o que se passa entre os pais negros que enviam seus filhos para essa linha de luta. A criança deve ser capaz de resistir - ela é um Negro, e deve dominar essas tensões, e caso se machuque, será mais um sacrifício. ${ }^{5}$

Segundo conta Young-Bruehl (1977, p. 436), Arendt responde para Ellison em carta, em 25 de julho de 1965, na qual escreve: "É exatamente esse ideal do sacrifício que eu não tinha compreendido”. Mas a miopia de Arendt sobre a causa dos negros por direitos nos EUA não havia cessado. Ainda em 1965, a autora publica o artigo "Sobre a violência”, no qual emite sua opinião sobre a juventude negra universitária:

\begin{abstract}
A violência séria só entrou em cena com o aparecimento do movimento Poder Negro nos recintos universitários. Estudantes negros, a maioria dos quais admitidos sem qualificação acadêmica, se consideravam e se organizavam como um grupo de interesses - os representantes da comunidade negra. Seu interesse era rebaixar os padrões acadêmicos [...] parece que a instituição acadêmica, na sua curiosa tendência de ceder mais às exigências dos negros, ainda que sejam abertamente ultrajantes e tolas, do que às reivindicações desinteressadas e por vezes altamente morais dos rebeldes brancos (ARENDT, 2015, p. 106).
\end{abstract}

A invisibilidade dos negros norte-americanos enquanto seres políticos gerou desconforto não só naquele momento. Até hoje causa certa estranheza a opinião de Arendt, ao ser contrária à integração escolar dos negros, bem como a manutenção de sua opinião sobre os negros em "Origens do Totalitarismo" (2016), considerados como "selvagens" em texto publicado em 1951, revisto pela autora em 1967. A revisão poderia demonstrar que a autora teria repensado suas ideias, tentado compreender a história de luta dos negros ou mesmo demonstrar-se aberta ao diálogo, mas o texto permaneceu igual ao original.

\title{
RECONCILIAÇÃO E EDUCAÇÃO
}

Na diáspora negra, seres humanos foram reduzidos a coisas, tendo suas histórias usurpadas. Porém, deve-se compreender que são histórias diferentes, com destinos diferentes, cujos reflexos são percebidos nos dias atuais. Pessoas negras continuam sendo vítimas da violência que se entranhou na mentalidade das sociedades. Como exemplo disso, o filho de

\footnotetext{
"This is where Hannah Ernst is way off in left base in her reflections on the Little Rock. She has no conception of what goes on in the parentes who send their kids through these lines. The kid supposed to be able to go through the line - he's a Negro, and he's supposed to have mastered those tensions, and if he gets hurt then this is one more sacrifice" (WARREN, 2014, p. 325).
} 
Elizabeth Eckford, Erin Eckford, foi morto aos 26 anos pela polícia em 2003 (TAYLOR, 2008). Esse tipo de violência não ocorre só nos EUA, mas também, cotidianamente, na sociedade brasileira e na africana, por exemplo. Conforme notícias divulgadas em diversos jornais, a violência pós-colonial ainda se faz sentir pela exploração por países europeus que colonizaram o continente negro, seja no antigo regime do apartheid sul-africano, seja no genocídio em Ruanda, em 1996.

A dor e o sofrimento dos judeus que foram mortos pela máquina do mal radical do nazismo devem ser contados. Da mesma forma, no mesmo grau, as agruras da voz dos negros que reivindicavam por direitos, após séculos, também devem ser ouvidas e contadas, para que sejam compreendidas e não esquecidas. Esse é um esforço para que os discursos de preconceito não se tornem uma prática que parte dos intelectuais reproduz sem que possa compreender.

Não há dúvida de que tal posicionamento adotado por Arendt em "Reflexões sobre Little Rock" ainda hoje ressoa como uma provocação para as minorias que lutam por seus direitos mais básicos, como o da própria vida. Em um modelo de sociedade no qual os negros eram proibidos de adentrar espaços de pessoas brancas, sob o risco de morte caso ultrapassassem a linha divisória entre o branco e negro, desde crianças estes eram tratados de modo diferenciado nos espaços públicos, como ônibus, praças, escolas. Nessa perspectiva, deve-se pensar a educação inserida no terreno político, a qual inclui a formação das crianças e jovens.

A atitude defendida pela NAACP, instituição que luta pelos direitos civis das pessoas negras nos EUA, foi criticada por Arendt como luta de cunho social, não político. A autora não percebeu que a reinvindicação por educação não segregada e de qualidade não diz respeito apenas ao direito das crianças e jovens negros, excluídos por um longo tempo do processo de escolarização, mas de todos que convivem no mundo comum.

É evidente que as crianças precisam ser protegidas, e que os adultos devem cuidar para que não sejam humilhadas por outras crianças ou por professores na escola. Nesse sentido, a escola ainda não é o espaço público propriamente dito. Por outro lado, todas as crianças, isto é, todos que nascem no mundo, devem ter igual direito à educação, para conhecer e compreender a existência das diferenças na escola, mesmo que de modo ainda protegido. Porém, Arendt desconhecia a história de Elizabeth, que, em entrevista à CNN (2004), disse: “Minha mãe era extremamente superprotetora”. 
Arendt tropeça sobre o tema da integração racial na escola, não apenas aos olhos de hoje, mas também de seus contemporâneos. Pensar a educação marca a defesa da diversidade, compreendida e vivenciada na escola, entre as crianças e os jovens, em tons diversos, com rostos, saberes e culturas. Com esses tons diversos, pode ser criado um espaço mais plural que tanto reivindicamos como comum a todos os seres humanos.

Gilberto Gil, cantor e compositor negro baiano, filho de médico, estudante de colégio tradicional frequentado pela elite soteropolitana, lembra, em sua canção “Tradição” (GIL, 1979), da sua infância vivenciada na década de 1950 na Bahia, na qual ouvia "que preto não entrava no Bahiano [Tênis Clube], nem pela porta da cozinha". Trata-se de um clube social da elite baiana do qual os negros não poderiam participar, independentemente de sua condição social, mesmo sendo a Bahia formada por maioria da população de origem negra. Tal realidade era semelhante àquela vivida por pessoas negras no Sul dos EUA, que não poderiam participar dos mesmos espaços comuns aos brancos.

A convivência no espaço escolar, com toda essa diversidade, ocorre sob a autoridade de uma geração mais velha: os professores, que podem contar histórias das experiências dos antepassados sobre o mundo. Para que a geração mais nova possa conhecer e compreender que há uma história que a precedeu, seja a de Zumbi dos Palmares, seja a de Martin Luther King, seja a de Albert Einstein, cada uma delas importa tanto às crianças negras quanto às brancas. Assim também as histórias das mulheres: como a da própria Hipátia, a filósofa egípcia, Maria Felipa de Itaparica e Marielle Franco importam aos homens e às mulheres e também devem ser descobertas.

$\mathrm{Na}$ educação, as crianças conhecem as lutas e reivindicações das gerações passadas, expressas em histórias. Assim, compreender a história dos Little Rock Nine é encontrar o novo. Quando aqueles alunos efetivamente adentraram a Little Rock Central High School, constituiu-se uma atitude permanente para que os negros norte-americanos pudessem se reconciliar pelos eventos vivenciados não apenas por aquela geração, mas por todas as gerações que a antecederam e lutaram pelo reconhecimento de seus direitos sociais e políticos. Sem romper aquela linha, antecedida pela batalha política do movimento negro, enfrentada diariamente também nos pátios da escola por aqueles nove jovens e os que vieram depois deles, sem a experiência da integração escolar não haveria a possibilidade do inesperado, isto é, do novo. Sem esse enfrentamento, além de outras conquistas do movimento negro norte-americano, para que ocorresse a integração racial nas escolas, 
dificilmente vislumbrar-se-ia a eleição de Barack Obama, em 2009, à presidência dos EUA. Assim lembra Obama em seu discurso de posse, em que, após agradecer os "sacrifícios suportados por nossos ancestrais", falou:

Esse é o significado de nossa liberdade e nosso credo - a razão por que homens e mulheres e crianças de todas as raças e todas as fés podem se unir em comemoração neste magnífico espaço, e por que um homem cujo pai, menos de 60 anos atrás, talvez não fosse atendido em um restaurante local hoje pode se colocar diante de vocês para fazer o juramento mais sagrado

(OBAMA, 2009).

Mesmo em meio à letargia da ideia mítica da existência da democracia racial, as pessoas afrodescendentes e o povo brasileiro buscam reconciliarse com sua história e encontrar caminhos de descobertas. Essa busca por reconciliação inevitavelmente passa pela educação. Como exemplo disso, tem-se a publicação de leis fundamentais como a Lei 10.639/2003, ampliada pela Lei 11.645 , de 10 de março de 2008, que ressalta a importância da cultura negra e indígena na formação da sociedade brasileira, com a inclusão no currículo oficial da rede de ensino a obrigatoriedade da temática "História e Cultura Afro-Brasileira e Indígena" (ALBUQUERQUE; FRAGA, 2006). Além desse, a luta, por mais de 12 anos, pelo direito ao sistema de cotas raciais, para negros e indígenas, nas universidades públicas, que teve sua primeira implantação na Universidade do Estado do Rio de Janeiro (Uerj) em 2000, até a sanção da Lei das Cotas (Lei n. 12.711, de agosto de 2012).

A reconciliação na educação é o modo pelo qual se pode compreender que há um mundo plural, que as gerações compartilham. Os seres humanos, por meio da reconciliação, podem conceber a existência de um mundo no tempo. Mundo que passa de mão para mão entre as gerações, pois cada uma delas pode representar um novo começo, criando ou tentando dar continuidade, ou mesmo interrompendo as palavras e ações da precedente, mas nunca deixando de contar as experiências humanas sucedidas às próximas gerações. A esse respeito, em sua palestra intitulada "O perigo da história única”, a escritora nigeriana Chimamanda Ngozi Adichie (2009) argumenta: "As histórias também podem ser usadas para dar poder e para humanizar. As histórias podem quebrar a dignidade de um povo. Mas as histórias também podem reparar essa dignidade quebrada”.

Assim, pensar o passado ainda não contado às crianças e aos jovens, por meio de histórias das gerações anteriores que lutaram por seus direitos, é uma forma de luta contra uma única história. As diversas vozes e ações dessas gerações ainda perduram no tempo, por meio de suas histórias, porque todas as formas de experiências humanas, das mais diversas, precisam ser contadas aos mais 
novos, mesmo que retratem injustiças ou violências cometidas, assim como a história ocorrida com Elizabeth. Nesse mundo, que é mais velho, sobre o qual se tem a contar, os novos podem enxergar a possibilidade de serem protagonistas e de se inserirem na história, que começou antes deles, e na qual podem encontrar amigos, embora nela haja inimigos também.

\section{CONSIDERAÇÕES FINAIS}

A questão é que mesmo diante da tentativa de esforço e da simpatia de Arendt para com os negros norte-americanos, a autora não compreendeu a seriedade do acontecimento em Little Rock, nem a plenitude da luta pela causa dos direitos civis dos negros nos EUA. No caso da reinvindicação pela educação não segregada, empreendida pelas pessoas negras, essa luta estava acontecendo nos espaços políticos e também no espaço da educação. Assim, a conquista dessa educação não segregada resultou da luta empreendida em ambos os espaços, como consequência da força de transformação histórica e política da população negra, que foi escravizada e ainda nos dias atuais permanece à margem dos direitos básicos.

A invisibilidade é o racismo presente nos discursos dos intelectuais e das instituições, nos gestos e nas ações do dia a dia que geram violência contra os jovens negros. A violência contra a jovem Elizabeth se perpetua, ainda hoje, na sociedade norte-americana e no mundo, de diversas formas, como na morte de jovens negros nas periferias das cidades pelo mundo. Diante desse processo de invisibilidade, a cor da pele chega antes, numa tentativa de apagamento histórico da participação política dos negros.

Os negros, ao longo da história, foram ignorados enquanto seres políticos, vistos como objetos da natureza, e o olhar de Arendt acompanhou esse movimento histórico de invisibilidade. A autora expressou sua invisibilidade aos negros ao longo de seu pensamento, seja em "Origens do totalitarismo", seja no texto em questão, "Reflexões dobre Little Rock", seja no ensaio "Sobre a violência”. Tal indiferença vem, em parte, de ações ultrajantes e tolas dos negros, categorizadas para a ascensão social ou na afirmação de que a segregação constituía-se enquanto costume social. Nada mais horrível do que essas afirmações ditas pela grande pensadora do século XX.

A escola não é local para perpetuar discursos de invisibilidade, mas um ambiente propício aos encontros, onde as crianças e os jovens podem compartilhar uma história comum. Na educação ou em qualquer sociedade livre não há possibilidade de mundo segregado. 
Os negros norte-americanos buscavam quebrar as hierarquias sociais. Quando os pais negros exigiram que suas crianças tivessem igual acesso à educação como tinham as crianças brancas, constituiu-se uma resistência ao não segregar os seres humanos pela ideia de raça. Tratava-se de introduzir as crianças brancas e negras em um mesmo mundo comum, onde, juntas, quando adultas, poderiam criar e compartilhar laços políticos.

Portanto, Arendt não conseguiu compreender que os pais negros não abandonam suas crianças, nem as deixam sozinhas. Elizabeth estava acompanhada de seus antepassados, de uma história de luta contra a dessegregação e contra a invisibilidade racial nos EUA. Aquelas gerações agiram conscientemente como seres históricos e políticos porque consideravam a liberdade e a garantia de acesso à educação como fundamentais para que as crianças negras se apropriassem da história, da ciência e da cultura, que lhe foram negadas. Para aquela geração de pais negros, a educação de seus filhos era um assunto político, sim, e não um arrivismo social, como Arendt julgou. 


\section{Invisibility of the negro in Hannah Arendt's "Reflections on Little Rock": another history in education}

Abstract: The article discusses the story ignored by Hannah Arendt in the essay "Reflections on Little Rock". Following the determination of the US Supreme Court to integrate black and white children into the same schools, the government and part of the population in the city of Little Rock have violently blocked negroes' access to a regular school. In this context, a young black woman was photographed while being harassed by a horde of white people and prevented from entering school. From this photograph, Arendt writes one of his first texts in which she approaches the subject of education. Based on the bibliographical references that analyze the historical period in question, my aim here is to narrate another story, invisible by Arendt, problematizing if the thinker before analyzing racial desegregation in schools, dialogued with the history of North American blacks. Finally, it is concluded that education is an area of struggle against invisibility, against the danger of telling a single story to children and young people.

Keywords: Education. Invisibility. Negroes. Hannah Arendt. 


\section{Invisibilidad de los negros en "Reflexiones sobre Little Rock" de Hannah Arendt: una otra historia en la educación}

Resumen: El artículo discute la historia ignorada por Hannah Arendt en el ensayo "Reflexiones sobre Little Rock". Después de la determinación de la Corte Suprema Norteamericana para integrar a niños negros y blancos en las mismas escuelas, el gobierno y parte de la población en la ciudad de Little Rock bloquearon violentamente el acceso de los negros a una escuela común. En ese contexto, una joven negra fue fotografiada mientras era hostilizada por una horda de personas blancas e impedida de entrar en la escuela. A partir de esa fotografía, Arendt escribe uno de sus primeros textos el que aborda el tema de la educación. Con base en las referencias bibliográficas que analizan el período histórico en cuestión, se objetiva narrar otra historia, invisibilizada por Arendt. El texto problematiza si la pensadora antes de analizar la desegregación racial en las escuelas, dialogó con la historia de los negros norteamericanos. Por último, se concluye que la educación es un espacio de lucha contra la invisibilidad, contra el peligro de contar una sola historia a los niños y a los jóvenes.

Palabras clave: Educación. Invisibilidad. Negro. Hannah Arendt. 


\section{REFERÊNCIAS}

ADICHIE, C. N. O perigo de uma história única. 2009. Disponível em: https:// www.ted.com/talks/chimamanda_adichie_the_danger_of_a_single_story/tr anscript?language=pt\#t-1110073. Acesso em: 24 jan. 2018.

ALBUQUERQUE, W. R.; FRAGA, W. Uma história do negro no Brasil. Salvador: Centro de Estudos Afro-Orientais; Brasília: Fundação Cultural Palmares, 2006. ARENDT, H. The portable Hannah Arendt. USA: Penguin Books, 2000.

ARENDT, H. Responsabilidade e julgamento. São Paulo: Companhia das Letras, 2004.

ARENDT, H. Compreender: formação, exílio e totalitarismo (1930-1954). Tradução Denise Bottmann. 1. ed. São Paulo: Companhia das Letras; Belo Horizonte: Editora UFMG, 2007.

ARENDT, H. Entre o passado e o futuro. 6. ed. Tradução Mauro W. Barbosa. São Paulo: Perspectiva, 2011.

ARENDT, H. Crises da República. 2. ed. São Paulo: Perspectiva, 2015.

ARENDT, H. Origens do totalitarismo. Tradução Roberto Raposo. São Paulo: Companhia das Letras, 2016.

BAEHR, P. Introduction. In: ARENDT, H. The portable Hannah Arendt. USA: Penguin Books, 2000.

BOHMAN, J. The moral costs of political pluralism: the dilemmas of difference and equality in Hannah Arendt's "Reflections on Little Rock". In: MAY, L.; KOHN, J. Hannah Arendt: twenty years later. Cambrigde: MIT Press, 1997.

CNN. Eckford: Central High in 1957. 2004. Disponível em: http://edition.cnn. com/2004/LAW/05/17/eckford.transcript/. Acesso em: 10 jul. 2017.

ELLISON, R. Homem invisível. Tradução Mauro Gama. 1. ed. Rio de Janeiro: José Olympio, 2013.

GIL, G. Tradição. In: Realce. Rio de Janeiro, WEA, Elektra, 1979. Disco de vinil, faixa 4.

MAY, L.; KOHN, J. Hannah Arendt: twenty years later. Cambrigde: MIT Press, 1997. 
OBAMA, B. Barack Obama's Inaugural Address. The New York Times, New York, 29 jan. 2009. Disponível em: http://www.nytimes.com/2009/01/20/us/ politics/20text-obama.html. Acesso em: 1ํ set. 2017.

TAYLOR, Q. From Timbuktu to Katrina: sources in African-American history. Boston: Wadsworth Publishing, 2008. (v. 2).

UNITED STATES COURTS. Brown vs. Board of Education of Topeka. 1954. Disponivel em: http://www.uscourts.gov/sites/default/files/brown-boardeducation-re-enactment.pdf. Acesso em: 10 jul. 2017.

YOUNG-BRUEHL, E. Hannah Arendt's storytelling. Social Research, v. 44, n. 1, p. 183-190, Spring 1977.

WARREN, R. P. Who speaks for the Negro? New Haven: Yale University Press, 2014.

SOBRE O AUTOR:

Carlos Eduardo Gomes Nascimento é mestre em Educação pela Universidade Federal da Bahia. Atua como professor de filosofia da rede estadual da Bahia.

E-mail: carlos_gomes02@hotmail.com

Recebido em: dezembro de 2018

Aprovado em: abril de 2019 